\title{
A Novel Technique in Fibrin Gluing of Intercostal Nerves: Splint and Weld
}

\author{
Prem Singh Bhandari ${ }^{1}$ \\ ${ }^{1}$ Department of Plastic Surgery, Brij Lal Superspecialty Hospital, \\ Haldwani, Nainital, Uttarakhand, India
}

Indian J Plast Surg:2020;53:298-300

\begin{abstract}
Address for correspondence Prem Singh Bhandari, MS, MCh (Plastic surgery), Department of Plastic Surgery, Brij Lal Superspeciality Hospital, Haldwani, Nainital, Uttarakhand, 263139, India (e-mail: doctorbhandari@hotmail.com).
\end{abstract}
Abstract
Keywords
- Fibrin glue
- intercostal nerves
- musculocutaneous
nerve

Splint and weld technique ensures a sound coaptation of intercostal and musculocutaneous nerves with minimal introduction of synthetic suture through the neural tissue.

\section{Introduction}

Traditionally, nerve coaptation has been achieved by way of suturing. Challenges encountered during this procedure in the form of an uneven tension, skewed alignment, trauma to nerve fascicles from microinstruments, and foreign body reaction to synthetic suture, often lead to loss of regenerative axons with resultant suboptimal functional outcomes. Recent trends of using fibrin glue in nerve repair can yield results akin to suturing in experienced hands, and has the potential of being superior when the surgeon is less conversant with microsurgical techniques. ${ }^{1}$ Fibrin glue creates an adhesive cylinder around the stumps of the nerve through which regenerating axons grow by chemotaxis. ${ }^{2}$

The new technique described here takes advantages of both suture and glue fixation without introducing foreign material through the actual neural tissue and at the same time ensuring a sound coaptation.

\section{Description of Technique}

Distal $2.5 \mathrm{~cm}$ segments of three intercostal nerves are placed parallel on a thin plastic sheet ( $\mathbf{- F i g . ~ 1 )}$ ) and splinted with a layer of fibrin glue ( - Fig. 2). Approximately 60 seconds later, on formation of a coagulum, the glued edge of intercostal nerves is freshened with sharp microscissors. Thereafter, three 10/0 nylon sutures are passed through the edges of coagulum and the epineurium of the musculocutaneous nerve at 3, 6 and 12 o' clock positions ( - Fig. 3). Placement of microsutures through the soft and fragile coagulum requires a gentle and careful handling. A tension-free approximation is ensured without buckling of fascicles. Finally, the site of coaptation is welded with a layer of fibrin glue ( - Fig. 4). -Fig. 5 depicts a line diagram illustration of the technique. In the entire process, approximately $2 \mathrm{~mL}$ of reconstituted fibrin glue is consumed.

\section{Discussion}

Synthetic microsutures have traditionally been used in nerve coaptation. However, being foreign, material sutures are known to produce local inflammatory reaction that might hamper regeneration. ${ }^{1}$ These pathologic processes cause hindrance to the sprouting axons and impair blood supply to the fascicles. Suturing of thin caliber nerves, for example, intercostal nerves, may also be difficult and technically challenging. Use of fibrin glue obviates suture-related problems. Fibrin glue forms an adhesive cylinder around the nerve ends and allows axonal migration by chemotaxis. ${ }^{2,3}$

Intercostal nerve to musculocutaneous nerve neurotization is a standard procedure in restoration of elbow flexion. Usually, three intercostal nerves are coapted to musculocutaneous nerve using nylon suture or fibrin glue. Being thin and fragile, each intercostal nerve does not allow placement of more than a single suture. Suturing itself causes microtrauma and inflammatory reaction, even with sutures as thin as $10 / 0$, apart from the possibility of mismatch between sensory and

\section{License terms}

(ㄱ)(1) $\ominus \circledast$ 


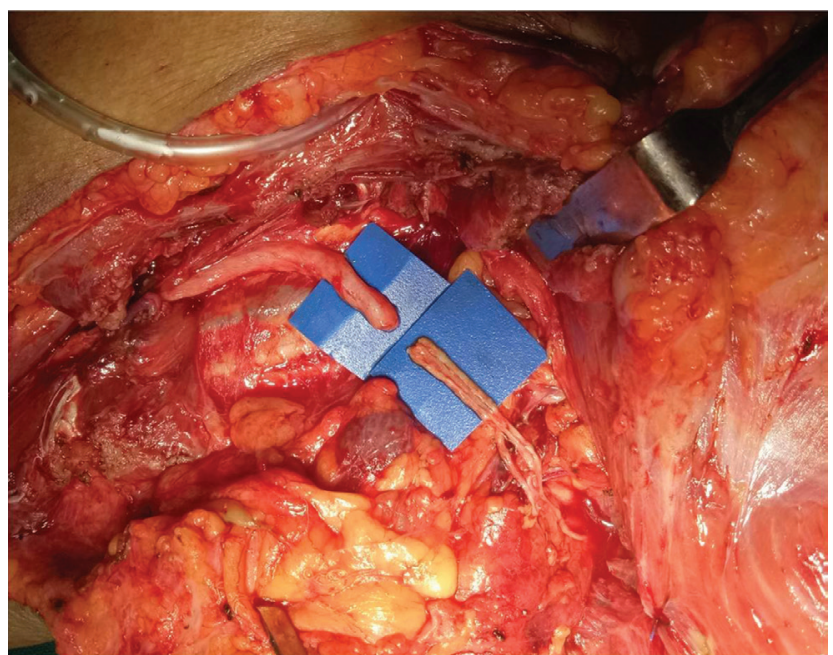

Fig. 1 Three intercostal nerves placed on a thin plastic sheet.

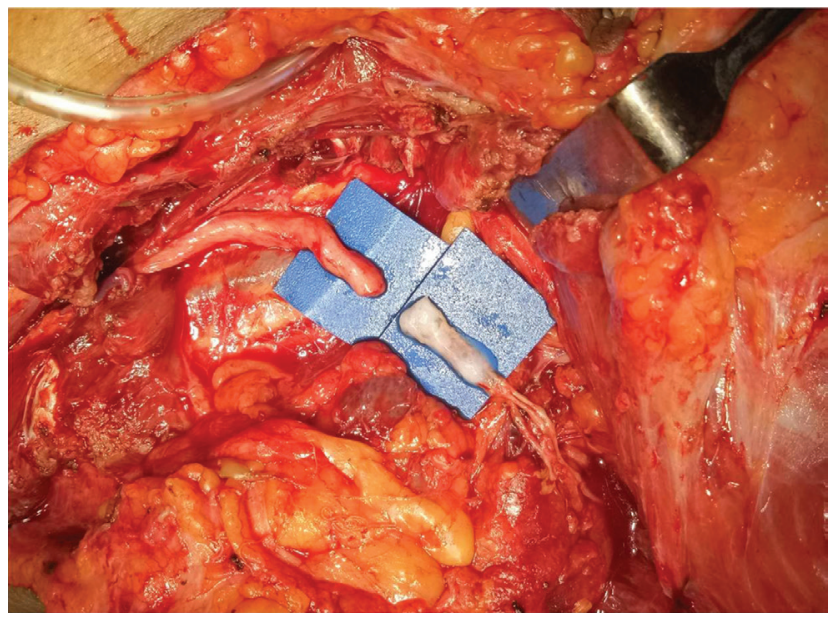

Fig. 2 Intercostal nerves are splinted with fibrin glue.

motor fascicles. These problems are obviated with fibrin glue fixation, ${ }^{4,5}$ although the strength at coaptation site with glue fixation alone remains the subject of concern. Suture and weld technique take advantages of both suture and glue fixation, without introducing foreign material through the actual neural tissue and at the same time ensuring a sound coaptation. This technique has been used in adult (six patients) as well as birth-related (11 patients) brachial plexus palsy patients. In the adult group, three patients restored M3, two patients M2, and a single patient M1 elbow flexion at 14 months follow-up. Results have been more encouraging in the birth palsy group, with nine patients attaining M3, and two patients M2 at 10 months follow-up. When compared with conventional techniques, the functional gains in attainment of

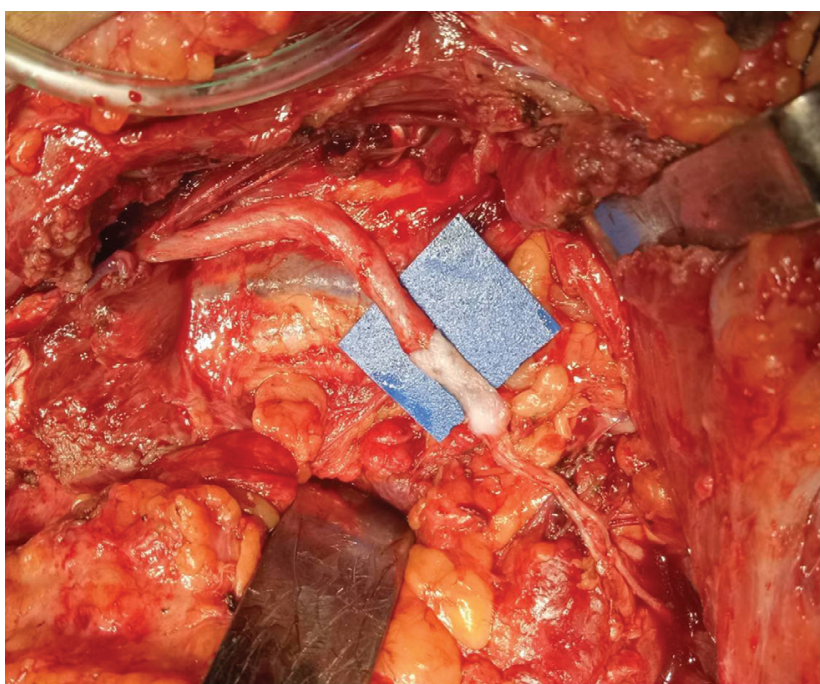

Fig. 3 Intercostal nerves have been coapted with musculocutaneous nerve with three $10 / 0$ sutures passed at 3, 6 and 12 ' o clock positions.

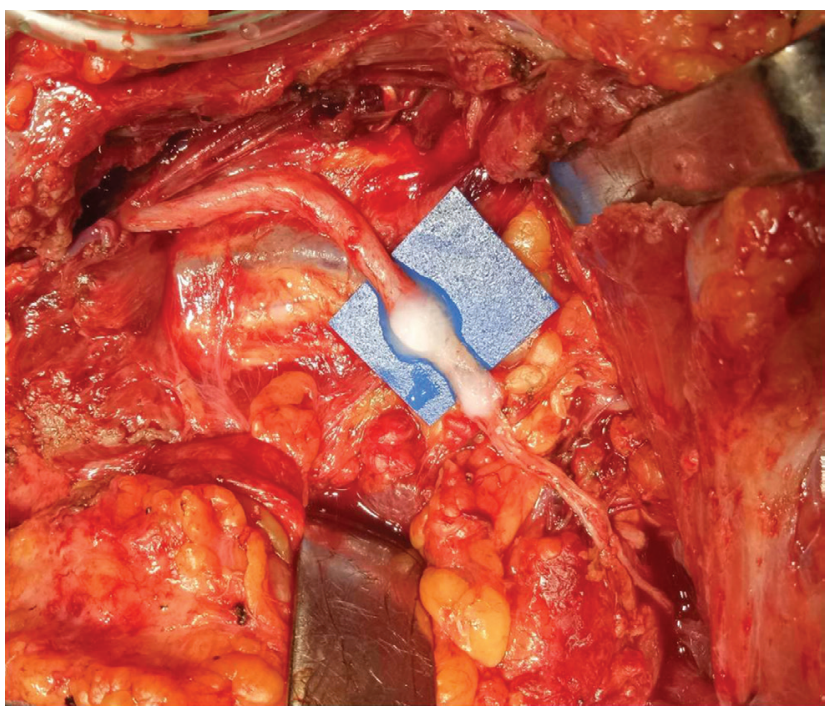

Fig. 4 Coaptation site is then welded with a layer of fibrin glue.

active elbow flexion have been superior with splint and weld technique.

\section{Conclusion}

This technique has dual advantage of both suturing as well as glue coaptation. Placement of sutures in extraneural tissue minimizes foreign body reaction, while splinting of distal segments of intercostal nerves ensures good approximation without loss of axons from misdirected fascicles. 


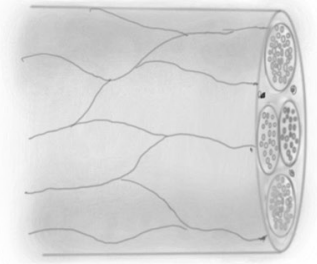

Musculocutaneous nerve

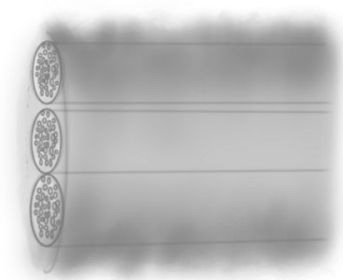

Three intercostal nerves splinted with fibrin glue (a)

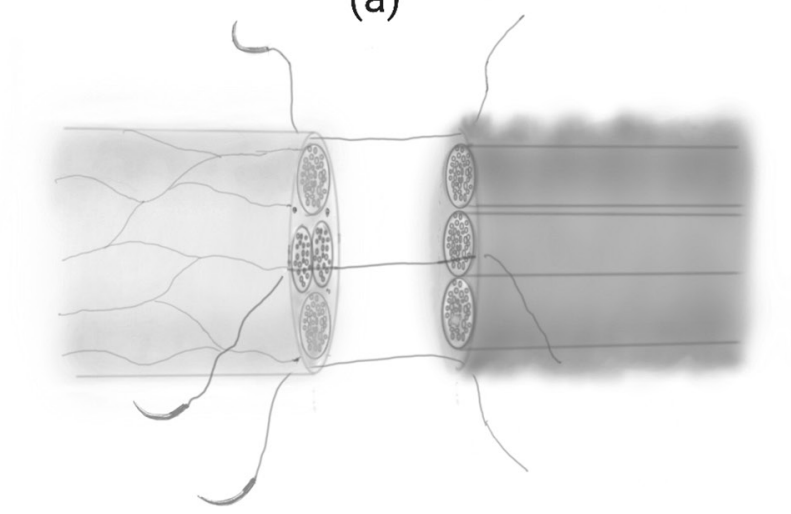

Microsutures passed through the glue and epineurium of musculocutaneous nerve

(b)

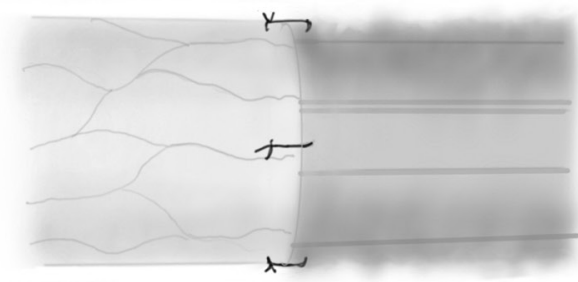

Suture approximation

(c)

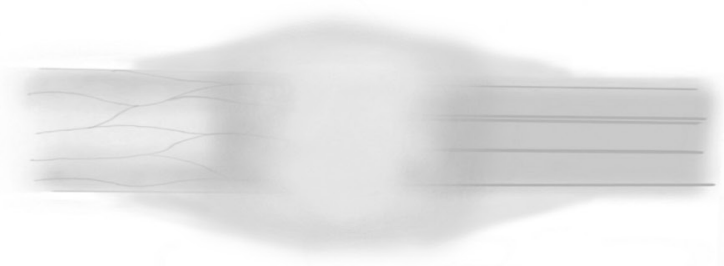

Coaptation site welded with a layer of fibrin glue

(d)

Fig. 5 Line diagram illustration of the technique.

\section{Financial support and sponsorship}

Nil.

\section{Conflicts of interest}

None declared.

\section{Acknowledgment}

Dr. Amborish Nath for line diagram illustration.

\section{References}

1 Suri A, Mehta VS, Sarkar C. Microneural anastomosis with fibrin glue: an experimental study. Neurol India 2002;50(1):23-26
2 Narakas A. The use of fibrin glue in repair of peripheral nerves. Orthop Clin North Am 1988;19(1):187-199

3 Palazzi S, Vila-Torres J, Lorenzo JC. Fibrin glue is a sealant and not a nerve barrier. J Reconstr Microsurg 1995;11(2):135-139

4 Menovsky T, Bartels RH. Stabilization and accurate trimming of nerve ends: practical use of fibrin glue: technical note. Neurosurgery 1999;44(1):224-225, discussion 225-226

5 Bhandari PS. Use of fibrin glue in the repair of brachial plexus and peripheral nerve injuries. Ind $\mathrm{J}$ Neurotruma. 2013;10:30-32 